\title{
Pediatric Traumatic Brain Injury: a 5-year descriptive study from the National Trauma Center in Qatar
}

\author{
Ayman El-Menyar ${ }^{1,2^{*}}$ (D), Rafael Consunji ${ }^{3}$, Hassan Al-Thani ${ }^{4}$, Ahammed Mekkodathil ${ }^{2}$, Gaby Jabbour ${ }^{4}$ and
} Khalid A. Alyafei ${ }^{5}$

\begin{abstract}
Background: The epidemiologic characteristics and outcomes of pediatric traumatic brain injury (pTBI) have not been adequately documented from the rapidly developing countries in the Arab Middle East. We aimed to describe the hospital-based epidemiologic characteristics, injury mechanisms, clinical presentation, and outcomes of pTBI and analyze key characteristics and determinant of pTBI that could help to make recommendations for policies to improve their care.

Methods: We conducted a retrospective observational study in a level 1 trauma center (2010-2014) for all pTBI patients. Data were analyzed and compared according to different patient age groups.

Results: Out of 945 traumatic brain injury patients, 167 (17.7\%) were $\leq 18$ years old with a mean age of $10.6 \pm 5.9$ and $81 \%$ were males. The rate of pTBI varied from 5 to 14 cases per 100,000 children per year. The most affected group was teenagers (15-18 years; $40 \%)$ followed by infants/toddlers ( $\leq 4$ years; $23 \%$ ). Motor vehicle crash (MVC; 47. $3 \%$ ) was the most frequent mechanism of injury followed by falls (21.6\%). MVC accounted for a high proportion of pTBI among teenagers (77.3\%) and adolescents (10-14 years; 48.3\%). Fall was a common cause of pTBI for infants/ toddlers (51.3\%) and 5-9 years old group (30.3\%). The proportion of brain contusion was significantly higher in adolescents (61.5\%) and teenagers (58.6\%). Teenagers had higher mean Injury Severity Scoring of $24.2 \pm 9.8$ and lower median (range) Glasgow Coma Scale of $3(3-15)(P=0.001$ for all). The median ventilatory days and intensive care unit and hospital length of stay were significantly prolonged in the teenage group. Also, pTBI in teenage group showed higher association with pneumonia (46.4\%) and sepsis (17.3\%) than other age groups $(P=0.01)$. The overall mortality rate was 13\% ( $n=22)$; 11 died within the first $24 \mathrm{~h}, 7$ died between the second and seventh day and 4 died one week post-admission. Among MVC victims, a decreasing trend of case fatality rate (CFR) was observed with age; teenagers had the highest CFR (85.7) followed by adolescents (75.0), young children (33.3), and infants/toddlers (12.5).
\end{abstract}

Conclusions: This local experience to describe the burden of pTBI could be a basis to adopt and form an efficient, tailored strategy for safety in the pediatric population.

Keywords: Trauma, Head injury, Pediatric, Brain injury, Road traffic, Falls

\footnotetext{
* Correspondence: aymanco65@yahoo.com

This study was presented in part at the 45 th Critical Care Congress (SCCM)

on February 20-24, 2016, Orlando, Florida, USA.

${ }^{1}$ Clinical Research, Trauma Surgery Section, Hamad General Hospital, Doha,

Qatar

${ }^{2}$ Clinical Medicine, Weill Cornell Medical School, Doha, Qatar

Full list of author information is available at the end of the article
} 


\section{Background}

Traumatic brain injury (TBI) is a main cause of functional disability and death in children worldwide $[1,2]$. A report from Europe showed that, among children with blunt head trauma, the rate of fatal and nonfatal TBI was 0.5 and 5.2 per 1000 children, respectively [3]. Younger children are most likely to incur a TBI from falls, whereas adolescents with TBIs are most commonly injured in MVCs and sports-related trauma [4]. An earlier study from Qatar reported MVCs and falls as the most frequent mechanisms of injury among children sustaining severe blunt trauma in 2011 [5].

Some studies have suggested that even children with mild injuries are at increased risk of functional disabilities that might occur in pediatric TBI (pTBI) up to 1 year from the initial injury $[6,7]$. Despite the fact that clinical advancements in the care of critically injured children have reduced fatalities in pTBI, the worse functional outcomes are still relying on the severity and type of head injury [8]. To date, the epidemiologic characteristics and outcomes of pTBI have not been adequately documented from the rapidly developing countries in the Arab Middle East. The objectives of this study are to describe the hospital-based epidemiologic characteristics, injury mechanisms, clinical presentation, and outcomes of pTBI in Qatar. We also analyze key characteristics and determinants of pTBI that could, whenever possible, make recommendations for policies to improve their care, reduce their adverse health outcomes, and promote their prevention.

\section{Methods}

This is a retrospective review of all pTBI cases, aged $\leq$ 18 years old, from the prospectively collected trauma registry of the Hamad Trauma Center (HTC), the national trauma center of Qatar, that treats all TBI cases in the country from 1 January 2010 to 31 December 2014. The HTC trauma registry is a mature database that participates in both the National Trauma Data Bank (NTDB) and the Trauma Quality Improvement Program (TQIP) of the American College of Surgeons-Committee on Trauma (ACS-COT).

All pTBIs in the trauma registry were identified by using the ICD-9 codes ranging from 800 to 959.9 (except ICD-9 codes 905-909.9; 910-924.9 and 930-939.9) and included in the study. Collected data included patient demographics, mechanism of injury, use of safety equipment, seating position in and status of ejection from the motor vehicle, Glasgow Coma Scale (GCS) at the scene and emergency department (ED), Injury Severity Score (ISS), head Abbreviated Injury Score (AIS), types of head injury, endotracheal intubation, intracranial pressure monitoring, neurosurgical procedures, hospital and ICU length of stay (LOS), ventilator days, in-hospital complications, and mortality.

Data were classified according to age groups as infants/toddlers (age 0-4 years), school age (5-9 years), adolescents (10-14 years), and teenagers (15-18 years) before analysis. This study was conducted in line with the STROBE checklist (Additional file 1).

The sample size was not prespecified as we intended to enroll all the patients $\leq 18$ years who sustained TBI and required admission. Selection bias was minimized as HTC at Hamad General Hospital (HGH), the only tertiary hospital, that deals with significant TBI, however, excluding patients who were not admitted might carry this bias. Data were presented as proportions, mean \pm standard deviation (SD) or median as appropriate. Differences in categorical and continuous variables were analyzed using $\chi^{2}$ test and one-way analysis of variance (ANOVA), as appropriate. Yates' corrected chi-square was used for categorical variables, if the expected cell frequencies were below 5 . A significant difference was considered when the two-tailed $P$ value was less than 0.05 . Data analysis was carried out using the Statistical Package for Social Sciences version 18 (SPSS Inc., Chicago, Illinois, USA).

\section{Results}

Out of the 945 TBI patients admitted to HTC during the study period, $167(17.7 \%)$ were children ( $\leq 18$ years) with a mean age of $10.6 \pm 5.9$ years, $81 \%$ were males. Table 1 shows the demographics, injury mechanisms, severity of injury, and outcomes among pTBI patients. MVC (47.3\%) was the most frequent mechanism of TBI followed by falls (21.6\%) and pedestrian injuries (10.8\%). Among MVCs, most frequently injured vehicle occupants were drivers and front seat passengers (23\% each). Only 5\% were using a seatbelt/restraint system, and 53\% were ejected from the vehicle during car crashes.

The median values of injury severity in the study population were indicative that at least half of all the patients had a severe injury and specifically a moderate to severe TBI, i.e., ISS was 19 (1-50), head AIS was 3 (1$5)$, and scene GCS was 9 (3-15). The majority of cases sustained severe TBI with lower scene GCS (70\%) as well as high head AIS (61\%), and $82.3 \%$ of them had polytrauma (ISS $\geq 16$ ). Based on the GCS at ED, the severity of injury was mild (12.2\%), moderate (22.6\%), and severe pTBI (65.2\%). Skull fracture (61.7\%) and brain contusion (49.7\%) were the most frequent CT scan findings followed by brain edema (30.7\%), subarachnoid hemorrhage $(24.2 \%)$, subdural hemorrhage $(24 \%)$, and epidural hemorrhage (13.8\%) (Fig. 1).

Table 2 presents the frequency and rate of pTBI per 100,000 populations during the study period, classified by gender. The rate of pTBI was low in 2010 (5.1 cases per 100,000 children per year), and it peaked in 2013 
Table 1 Demographics, injury mechanisms, and injury severity among pTBI patients $(n=167)$

\begin{tabular}{|c|c|}
\hline Variable & Value \\
\hline Age (years) (mean $\pm S D$ ) & $10.6 \pm 5.9$ \\
\hline Male gender & $136(81.4 \%)$ \\
\hline \multicolumn{2}{|l|}{ Nationality } \\
\hline Qatari-nationals & $78(46.7 \%)$ \\
\hline Non-nationals & $89(53.3 \%)$ \\
\hline \multicolumn{2}{|l|}{ Mechanisms of injury } \\
\hline Motor vehicle crash & $79(47.3 \%)$ \\
\hline Fall from height & $36(21.6 \%)$ \\
\hline Pedestrians & $18(10.8 \%)$ \\
\hline Motor cycle/bike & $7(4.2 \%)$ \\
\hline All-terrain vehicle crashes & $11(6.6 \%)$ \\
\hline Fall of heavy object & $6(3.6 \%)$ \\
\hline Gunshot wound & $2(1.2 \%)$ \\
\hline Others & $5(3 \%)$ \\
\hline \multicolumn{2}{|l|}{ Position in vehicle in MVC } \\
\hline Driver & 18/79 (22.8\%) \\
\hline Front passenger & 18/79 (22.8\%) \\
\hline Back passenger & 10/79 (12.6\%) \\
\hline Unspecified position & $33 / 79(41.8 \%)$ \\
\hline Seatbelt use in MVC & 4/79 (5.1\%) \\
\hline $\begin{array}{l}\text { Ejection from motor } \\
\text { vehicle in MVC }\end{array}$ & $42 / 70(53.2 \%)$ \\
\hline $\begin{array}{l}\text { Head Abbreviated Injury } \\
\text { Scale (mean } \pm \text { SD)/(median, range) }\end{array}$ & $3.5 \pm 0.9 / 3(1-5)$ \\
\hline $\begin{array}{l}\text { Injury severity score } \\
\text { (mean } \pm \mathrm{SD}) /(\text { median, range) }\end{array}$ & $20.7 \pm 9.8 / 19(1-50)$ \\
\hline $\begin{array}{l}\text { Glasgow Coma Score at Scene } \\
(\text { mean } \pm \mathrm{SD}) /(\text { median, range) }\end{array}$ & $8.7 \pm 4.3 / 9(3-15)$ \\
\hline Scene time (mean \pm SD) & $21.4 \pm 16.2$ \\
\hline $\begin{array}{l}\text { Emergency Medical Services } \\
\text { time (mean } \pm \text { SD) }\end{array}$ & $55.3 \pm 28$ \\
\hline Intubation & $129(77.2 \%)$ \\
\hline On-scene & $53(41 \%)$ \\
\hline $\begin{array}{l}\text { Emergency department/Trauma } \\
\text { Resuscitation Unit }\end{array}$ & $76(59 \%)$ \\
\hline Hospital stay & $10(1-131)$ \\
\hline ICU stay & $5(1-39)$ \\
\hline Ventilator days & $1.5(1-37)$ \\
\hline Mortality & $22(13.3 \%)$ \\
\hline
\end{tabular}

(13.8 cases per 100,000 children per year) with a slight drop in the last year of the study period. The rate of pTBI was disproportionately higher among males in comparison to females, but the male to female incidence rate ratio decreased by more than fourfold during the study period, from 13.3 to 3.1 male per female pTBI patient.

Table 3 demonstrates the demographics, mechanism of injury, and characteristics of pTBI patients classified by age group. The predominance of male patients was

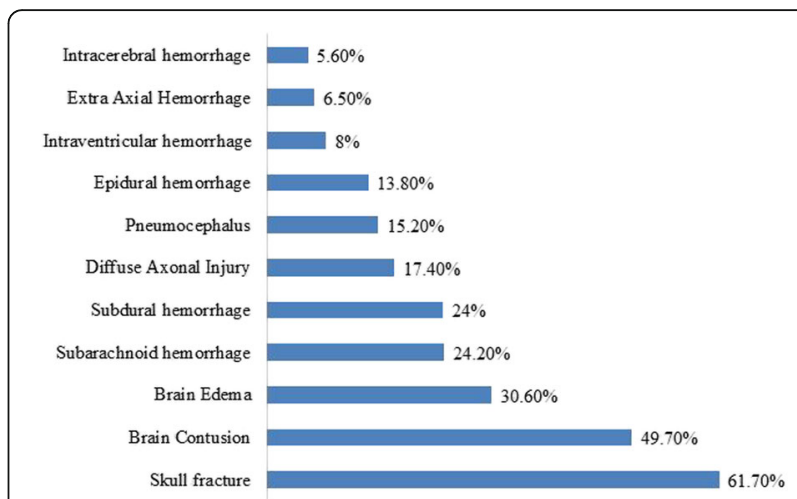

Fig. 1 Type and frequency of head injuries

consistent between all of the age groups. The majority of the local population with TBI was between 15 and 18 years [52.6\%]; expatriates, however, had most pTBI patients between $0-4$ [32.6\%] and $15-18$ years [28.1\%].

Table 4 shows the Emergency medical services (EMS) characteristics and interventions, type of head injury, neurosurgical interventions, injury severity, complications, and mortality among PTBI cases. Intubation at the scene was most common in the oldest age group, 1518 years, whereas the youngest age groups, $0-4$ and $5-$ 9 years, were most commonly intubated in the ED. Among the different types of head injuries, brain contusions showed a significantly higher incidence, with the two older age groups of pTBI patients. There were no statistically significant differences between the age groups for the other types of head injuries. Neurosurgical interventions, head AIS, and GCS (at scene) were comparable among different age groups. Although the head AIS showed no significant difference by age groups, it showed a trend towards higher scores in infants/toddlers and teenagers. Teenagers (15-18 years) had significantly higher mean ISS $(24.2 \pm 9.8)$ and lower median GCS ED [3 (3-15)] than the younger groups $(P=0.001)$.

Complications such as pneumonia and sepsis, ICU LOS, and ventilator days were significantly higher in the oldest age group. The overall mortality was $13.3 \%$ $(n=22)$ which was comparable among the different age groups $(P=0.43)$. Eleven $(50 \%)$ patients died within the first $24 \mathrm{~h}$, seven $(31.8 \%)$ died between $2-7$ days, and 4 (18.2\%) died after 1 week.

The case fatality rate (CFR) by the mechanism of injury in different age groups was presented in Table 5. The highest CFR was traffic-related in the ages between 10 and 18 , whereas it was fall-related in younger age (5-9 years).

\section{Discussion}

Pediatric TBI remains an important public health concern worldwide, which necessitates the adoption and implementation of strict prevention strategies based on the 
Table 2 pTBI rates per 100,000 population across the study duration

\begin{tabular}{lllllllllll}
\hline Year & $\begin{array}{l}\text { Male } \leq \\
18 \text { years }\end{array}$ & $\begin{array}{l}\text { Female } \\
\leq \\
18 \text { years }\end{array}$ & $\begin{array}{l}\text { Male to } \\
\text { female } \\
\text { ratio }\end{array}$ & $\begin{array}{l}\text { Total } \leq \\
18 \text { years }\end{array}$ & $\begin{array}{l}\text { Male pTBI } \\
\text { admissions }\end{array}$ & $\begin{array}{l}\text { Female } \\
\text { pTBI } \\
\text { admissions }\end{array}$ & $\begin{array}{l}\text { pTBI rates } \\
\text { per } 100,000 \\
\text { males }\end{array}$ & $\begin{array}{l}\text { pTBI rates per } \\
100,000 \\
\text { females }\end{array}$ & $\begin{array}{l}\text { Male to female } \\
\text { ratio (rate per } \\
100,000)\end{array}$ & $\begin{array}{l}\text { Overall pTBI rates } \\
\text { per 100,000 } \\
\text { population }\end{array}$ \\
\hline 2010 & 150,841 & 142,632 & 1.06 & 293,473 & 14 & 1 & 9.3 & 0.7 & 13.3 & 5.1 \\
2011 & 160,425 & 152,427 & 1.05 & 312,852 & 25 & 3 & 15.6 & 2.0 & 7.8 & 8.8 \\
2012 & 169,029 & 159,408 & 1.06 & 328,437 & 23 & 6 & 13.6 & 3.8 & 3.6 & 8.7 \\
2013 & 183,214 & 174,098 & 1.05 & 357,312 & 39 & 11 & 21.3 & 6.3 & 3.4 & 13.8 \\
2014 & 204,174 & 183,461 & 1.11 & 387,635 & 35 & 10 & 17.1 & 5.5 & 3.1 & 11.3 \\
Average & & & & & & 15.4 & 3.6 & 4.3 & 9.5
\end{tabular}

available local epidemiologic characteristics [9]. This is a unique study from the Arab Middle East to describe the epidemiologic characteristics and outcomes of a nationally representative population of pTBI classified by age group. There are several key findings in this study. First, one out of every six victims of TBI in Qatar is a child. Second, the leading mechanism of injury and outcomes of pTBI are age-dependent. Third, the most affected group is teenagers (40\%) followed by infants/toddlers (23\%). Fourth, two thirds of the cohort has severe pTBI. Fifth, males predominate among the victims but the gender difference is narrowing.

Eighteen percent of all TBI in Qatar, during the study period, were children, and according to the Qatar Statistics
Authority, $18 \%$ of the population of Qatar are children, aged 18 years or younger [10]. This denotes that children in Qatar do not bear a disproportionate risk for TBI, but at the same time, they are not more protected than adults from TBIs. An analysis of the leading age group-dependent mechanisms of injury, that cause pTBI in Qatar, will inform the creation of focused efforts to prevent these pTBIs.

There are few published studies on pTBI from the Gulf Cooperation Council (GCC) countries including Qatar. In 2012, Hefny et al. [11] reviewed the pediatric trauma research in the GCC and demonstrated a pediatric trauma publication rate of 0.16 publications per 100,000 populations. We have observed a high agespecific incidence and mortality in pTBI cases mainly

Table 3 Demographics and mechanism of injury and severity of pTBI based on different age groups

\begin{tabular}{|c|c|c|c|c|c|}
\hline Variable & $0-4$ years & $5-9$ years & 10-14 years & $15-18$ years & $P$ \\
\hline Number & $39(23.4 \%)$ & $33(19.8 \%)$ & $29(17.4 \%)$ & $66(39.5 \%)$ & \\
\hline Age (mean \pm SD) & $2.6 \pm 1.2$ & $6.4 \pm 1.2$ & $12.7 \pm 1.4$ & $16.6 \pm 1.1$ & 0.001 \\
\hline Males & $28(71.8 \%)$ & $26(78.8 \%)$ & $24(82.8 \%)$ & $58(87.9 \%)$ & 0.22 \\
\hline \multicolumn{6}{|l|}{ Nationality } \\
\hline Qatari-nationals $n=78$ & $10(12.8 \%)$ & $14(17.9 \%)$ & $13(16.7 \%)$ & $41(52.6 \%)$ & \multirow[t]{2}{*}{0.004 for all } \\
\hline Non-nationals $n=89$ & $29(32.6 \%)$ & $19(21.3 \%)$ & $16(18.0 \%)$ & $25(28.1)$ & \\
\hline \multicolumn{6}{|l|}{ Mechanism of injury } \\
\hline Motor vehicle crash & $8(20.5 \%)$ & $6(18.2 \%)$ & $14(48.3 \%)$ & $51(77.3 \%)$ & \multirow[t]{6}{*}{0.001 for all } \\
\hline Pedestrian injury & $5(12.8 \%)$ & $8(24.2 \%)$ & $5(17.2 \%)$ & $0(0.0 \%)$ & \\
\hline Falls from height & $20(51.3 \%)$ & $10(30.3 \%)$ & $2(6.9 \%)$ & $4(6.1 \%)$ & \\
\hline Motor cycle crash/bike & $0(0.0 \%)$ & $3(9.1 \%)$ & $2(6.9 \%)$ & $2(3.0 \%)$ & \\
\hline All-terrain vehicle & $0(0.0 \%)$ & $3(9.1 \%)$ & $4(13.8 \%)$ & $4(6.1 \%)$ & \\
\hline Fall of heavy object & $3(7.7 \%)$ & $1(3.0 \%)$ & $0(0.0 \%)$ & $2(3.0 \%)$ & \\
\hline Ejection from vehicle & $3(37.5 \%)$ & $3(50.0 \%)$ & $4(28.6 \%)$ & $29(56.9 \%)$ & 0.001 \\
\hline Scene time & $12.2 \pm 7.3$ & $16.6 \pm 11$ & $25.4 \pm 14$ & $26.9 \pm 19.9$ & 0.002 \\
\hline EMS time & $42 \pm 20$ & $44 \pm 18.7$ & $57.6 \pm 22.8$ & $67.6 \pm 32.8$ & 0.001 \\
\hline Severe TBI $(G C S<9)$ & $59 \%$ & $40.6 \%$ & $67.9 \%$ & $80 \%$ & 0.01 \\
\hline Glasgow Coma Score Scene; median(range) & $7(3-15)$ & $10(3-15)$ & $10(3-15)$ & $8.5(3-15)$ & 0.36 \\
\hline Glasgow Coma Score ED; median (range) & $7(3-15)$ & $10(3-15)$ & $5(3-15)$ & $3(3-15)$ & 0.001 \\
\hline Head AIS, mean \pm SD & $3.6 \pm 1.1$ & $3.1 \pm 0.8$ & $3.4 \pm 0.8$ & $3.6 \pm 0.9$ & 0.15 \\
\hline Injury severity score, mean \pm SD & $19.8 \pm 10.1$ & $15.6 \pm 8$ & $19.7 \pm 8$ & $24.2 \pm 9.8$ & 0.001 \\
\hline
\end{tabular}


Table 4 Type of head injury, interventions, and complications among pTBI patients

\begin{tabular}{|c|c|c|c|c|c|}
\hline Variable & $0-4$ years $(n=39)$ & $5-9$ years $(n=33)$ & $10-14$ years $(n=29)$ & $15-18$ years $(n=66)$ & $P$ \\
\hline \multicolumn{6}{|l|}{ Type of head injury (\%) } \\
\hline Skull fracture & 69 & 70 & 64 & 53 & 0.31 \\
\hline Brain contusion & 36.4 & 35.7 & 61.5 & 58.6 & 0.04 \\
\hline Subdural hemorrhage & 19.4 & 17.4 & 36.4 & 24.5 & 0.42 \\
\hline Epidural hemorrhage & 12.9 & 8.7 & 22.7 & 13.0 & 0.56 \\
\hline Extra axial hemorrhage & 3.4 & 12.5 & 5.3 & 5.9 & 0.58 \\
\hline Subarachnoid hemorrhage & 22.6 & 25.0 & 25.0 & 24.5 & 0.99 \\
\hline Intraventricular hemorrhage & 10.0 & 4.3 & 0.0 & 11.8 & 0.36 \\
\hline Intracerebral hemorrhage & 3.4 & 16.7 & 0.0 & 3.8 & 0.06 \\
\hline Pneumocephalus & 10.3 & 21.7 & 23.8 & 11.5 & 0.38 \\
\hline Brain edema & 34.4 & 23.1 & 27.3 & 33.3 & 0.75 \\
\hline Diffuse axonal injury & 9.7 & 15.4 & 14.3 & 24.1 & 0.36 \\
\hline ICP monitor insertion (\%) & 20.5 & 6.1 & 10.3 & 18.2 & 0.25 \\
\hline Craniotomy/craniectomy (\%) & 17.9 & 3.0 & 10.3 & 9.0 & 0.22 \\
\hline Intubation & $26(66.7 \%)$ & $20(60.6 \%)$ & $22(75.9 \%)$ & $61(92.4 \%)$ & 0.001 \\
\hline Intubation at scene & 15.4 & 15 & 41 & 61 & 0.001 \\
\hline Intubation at TRU/ED & 84.6 & 85 & 59 & 39 & 0.001 \\
\hline Hospital stay; median(range) & $7(1-98)$ & $7(1-38)$ & $10.5(2-76)$ & $19(1-131)$ & 0.001 \\
\hline ICU stay, median,(range) & $2.5(1-39)$ & $2(1-11)$ & $3(1-27)$ & $11(1-37)$ & 0.001 \\
\hline Ventilator days, median(range) & $1(1-37)$ & $1(1-6)$ & $1(1-21)$ & $5(1-27)$ & 0.001 \\
\hline Pneumonia (\%) & 6.7 & 0.0 & 23.8 & 46.4 & 0.001 \\
\hline Sepsis (\%) & 3.4 & 0.0 & 0.0 & 17.3 & 0.01 \\
\hline
\end{tabular}

involving teenagers and infants/toddlers. The mean age of pTBI cases in our study was 10 years which is similar to a recent study from a neighboring larger country (Saudi Arabia) with an average age of 8.6 years for pTBI admissions [12]. The present study estimates the hospitalization rate of pTBI to be 9.5 cases per 100,000 children per year, which ranges between 5 and 14 cases per 100,000 children per year. A recent study from Qatar reported the incidence of severe pediatric trauma to be 163 per 280,000 children ( $\leq 18$ years) who visited ED per year [5]. A previous report from our center identified that $28 \%$ of the TBI patients were under the age of 20 years old [13].

MVCs were the leading cause of pTBI in our study, accounting for $77.3 \%$ of the pTBIs in the $15-18$ years old group. A similar figure was reported in the Saudi Arabia
(74.4\%) for high school students [12]. In our series, the $57 \%$ ejection (from the vehicles) rate are inversely proportional to the $5 \%$ rate of seatbelt use. A recent publication from our center demonstrated that the underutilization of seatbelt among young vehicle occupants is associated with ejection and higher morbidities and mortality [14]. It has been estimated that seatbelt compliance could possibly result in twofold reduction in severe injury and fourfold reduction of mortality among MVC victims. Grivna et al. [15] reported 24\% fatality among unrestrained adolescent (10-14 years) drivers in the UAE. A cross-sectional survey conducted in Kuwait revealed the limited knowledge about child car safety among the parents. Nearly two out of five participants have either seated a child in the front seat or on their

Table 5 pTBI incidence and case fatality rate (CRF) by age groups and mechanism of injury (MOI)

\begin{tabular}{llllll}
\hline MOI & $0-4$ years $(n=39)$ & $\begin{array}{l}5-9 \text { years } \\
(n=33)\end{array}$ & $\begin{array}{l}10-14 \text { years } \\
(n=29)\end{array}$ & $\begin{array}{l}15-18 \text { years } \\
(n=66)\end{array}$ & $\begin{array}{l}\text { CFR by MOI } \\
\text { MVC }\end{array}$ \\
Pedestrian injury & $n=8$ & $n=6$ & $n=14$ & $n=0$ & 12.7 \\
Fall & $n=5$ & $n=8$ & $n=5$ & $n=4$ & $n$ \\
Other MOI & $n=20$ & $n=10$ & $n=2$ & $n=11$ & 11 \\
CFR by age group & $n=6$ & $n=9$ & 13.2 & 10.6 \\
\hline
\end{tabular}


lap while driving [16]. A roadside survey, conducted outside nurseries in Qatar, observed a 38\% appropriate utilization with an almost equal $41 \%$ incorrect utilization of car seats for children under 5 years. Additionally, 11\% of the more than 2000 children observed were improperly seated, unrestrained, and in the front seat [17]. In this study, a higher proportion of injured infants/toddlers, $37.5 \%$, were occupying the front seat of the vehicle, a clear violation of Qatar traffic regulations [17]. This finding highlights the need for more consistent enforcement of the existing laws on child passenger safety and the expansion of these laws that require the use of restraints for all vehicle passengers, children, and adults in all seating locations.

All Terrain Vehicle (ATV)-related pTBIs were most common among adolescents, 10-14 years, in our study, which is in line with a previous study on recreationalrelated injuries from Qatar [18]. In this study, bicyclerelated pTBI was most common in young children, 59 years, and the use of helmet was not reported or documented in any. These recreational or sports-related pTBIs among younger children 14 years and under are a call for the widespread education in bicycle and ATV safety in schools and the creation and enforcement of laws requiring the use of helmets and safety gear for all bicycle and ATV users.

During the study period, we noted that the rate of pTBI increased more than the double, from 5.1 to 13.8 cases per 100,000 children per year with a slight decrease in the year 2014. Whether this decrease is sustained will be the subject of future research.

Eighty percent of our pTBI patients were males, and the incidence rate of male pTBI was fourfold higher than females. Similarly, an over-representation of males was also observed in studies from $\operatorname{KSA}$ and $\operatorname{UAE}[12,19]$. The initial gender discrepancy could be partly explained by differential risk exposure which in our study was underage driving by young males. This risk factor has been previously identified and has been the focus of concerted efforts by multi-disciplinary stakeholder groups, but it still remains as a priority area for road safety in Qatar.

The present study shows a frequent association of fallrelated pTBI among infants/toddlers which is consistent with an earlier study from Qatar [13]. Studies from Saudi Arabia reported fall to be the most common mechanism for pTBI among children of age less than 6 years (45.6\%) and in the age up to 3 years (34\%) [12, 20]. Also, our findings showed that pedestrians constituted $11 \%$ of total pTBI victims, and the highest association was observed in the young age group (5-9 years). Similarly, Grivna et al. [19] showed that $15 \%$ of pTBI involved pedestrian-motor vehicle collisions mainly expatriates of age less than 10 years. Another study from
KSA reported a higher frequency of pedestrian (30.3\%) sustained pTBI from major trauma [12].

In our study, the CFR was higher in infants/toddlers (20.5\%) and adolescents (13.8\%). An earlier study from KSA reported a similar mortality rate $(20 \%)$ in late adolescents [12]. The most fatal mechanism of injury in our study was pedestrian hit by motor vehicle. Further investigation is required in this area using larger sample size.

Creating injury prevention programs to specifically prevent pTBIs must begin with specific evidence on the leading mechanism of disease for each age group. This allows for the application of interventions that are not only proven to work but also appropriate for the developmental stage of the child at risk. A description of the age-specific patterns of road traffic injuries in children in Qatar has been previously presented, and this study further adds to the evidence for child injury programs.

Based on this study, families with infants and young toddlers, $0-4$ years of age, should be the beneficiary of education and information campaigns to increase knowledge on ways to improve home safety, to prevent pTBIs from falls and falling objects, and road safety to increase child restraint use and pedestrian safety. For families with older children, 5-9 years, the highest risks for pTBI come from falls, pedestrian injuries, and from the precocious use of the road as pedestrians, cyclists, and ATV riders. Adolescents could be the beneficiary of schoolbased education in almost all aspects of safe road use, especially as ATV drivers, and the tighter enforcement of the minimum age for driving in Qatar, 18 years and above. Lastly, teenagers must pass through graduated driver licensing programs, the only proven means of reducing their risk from pTBI as drivers. Untested driver education programs must not be implemented as they have actually been proven to increase the odds of young driver involvement in MVCs.

The educational and awareness campaigns must not be limited only to parents but to also include all the caregivers, especially for the younger age groups who are under the supervision of nannies and/or day care center staff. The creation and consistent enforcement of restraint laws for passengers of all ages will be instrumental in reducing the unnecessary toll from pTBIs in Qatar. Lastly, we urge that multi-disciplinary injury prevention programs be implemented and evaluated to reduce pTBI [21]. To highlight the importance of pTBI in our region, we summarized the findings of the present study and other published studies on pediatric head trauma in the Middle Eastern population in Table 6 [12, 20, 22-29].

A potential limitation of this study is the retrospective design. Our registry does not capture comprehensive information on the crash details, height of fall, site of injury and detailed restraint use. Also, we may underestimate the 


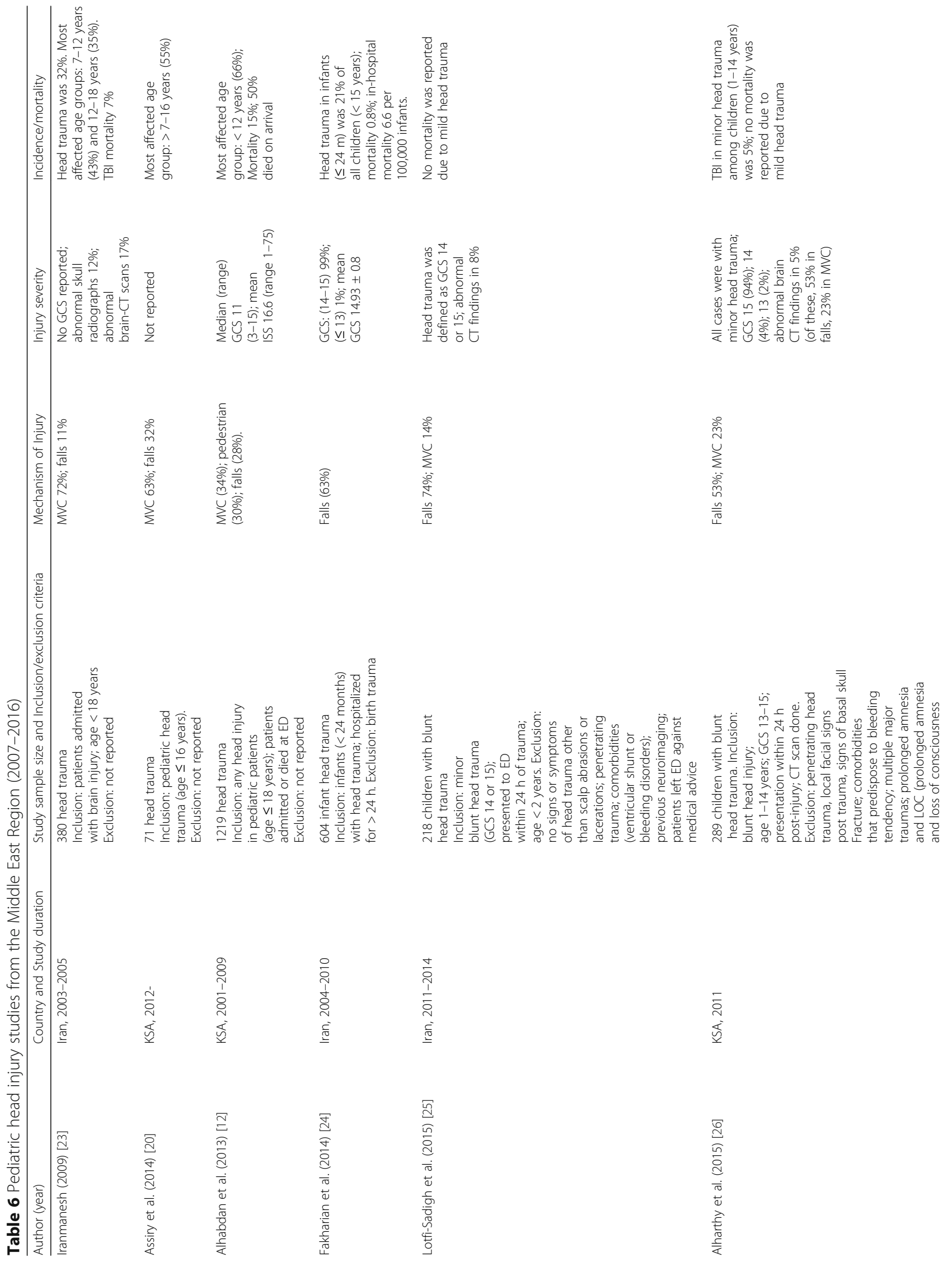




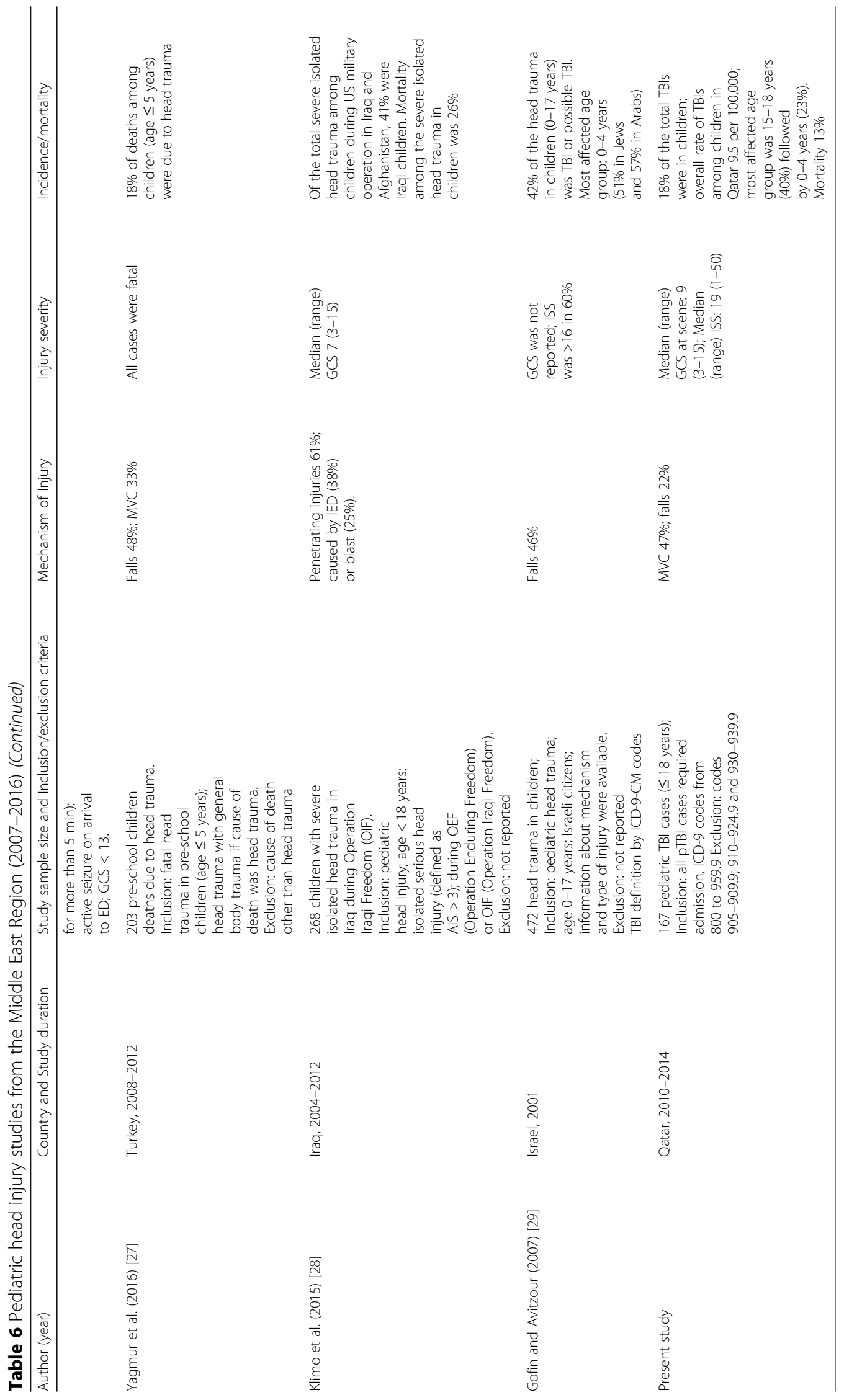


health burden from pTBI as it does not include patients who died at the scene, child abuse, long-term outcomes, and quality of life. The sample size was not prespecified as we intended to enroll all the patients $\leq 18$ years old who sustained TBI and required admissions. Selection bias was minimized as $\mathrm{HGH}$ is the tertiary hospital that deal with significant TBI; however, excluding patients who were not admitted might carry this bias.

\section{Conclusions}

The present study addresses the local burden of pTBI which could be the basis to develop efficient, tailored strategies and interventions for the community safety in our region. Targeted prevention programs are needed to reduce morbidity and mortality of pTBI.

\section{Additional file}

Additional file 1: STROBE CHECKLIST. (DOC $85 \mathrm{~kb}$ )

\section{Acknowledgements}

The authors thank the entire registry database team in the Trauma Surgery Section, Hamad General Hospital, Doha, Qatar.

\section{Funding}

This research did not receive any specific grant from any funding agency in the public, commercial, or not-for-profit sector.

\section{Availability of data and materials}

Anonymous data will be available after getting permission according to the medical research center (MRC) policy at HMC, Qatar; research@hamad.qa.

\begin{abstract}
Author's contributions
AE contributed to the study design, data analysis and interpretation, and drafting and critical review of manuscript. RC was involved in the study design, data acquisition, writing of the manuscript, and review. AM and GJ contributed to the data acquisition, interpretation, and drafting of the manuscript. KA and HA contributed to the study design, data interpretation, and critical review. All authors read and approved the final manuscript.
\end{abstract}

\section{Ethics approval and consent to participate}

This study obtained ethical approval from Research Ethics Committee, at Medical Research Center, Hamad Medical Corporation (HMC), Doha, Qatar (IRB\#15093/15).

This is a retrospective analysis with no direct contact with participants, and data were collected anonymously. Therefore, the medical research center granted a waiver of consent.

\section{Consent for publication}

This study was granted a waiver of consent and permission for publication from the medical research center (IRB\#15093/15).

\section{Competing interests}

The authors declare that they have no competing interests.

\section{Publisher's Note}

Springer Nature remains neutral with regard to jurisdictional claims in published maps and institutional affiliations.

\section{Author details}

'Clinical Research, Trauma Surgery Section, Hamad General Hospital, Doha, Qatar. ${ }^{2}$ Clinical Medicine, Weill Cornell Medical School, Doha, Qatar. ${ }^{3} \mathrm{Hamad}$ Injury Prevention Program, Trauma Surgery Section, Hamad General Hospital, Doha, Qatar. ${ }^{4}$ Trauma Surgery Section, Hamad General Hospital, Doha, Qatar.
${ }^{5}$ Department of Pediatrics, Division of Pediatric Emergency Medicine, Hamad Medical Corporation, Doha, Qatar.

Received: 13 September 2017 Accepted: 26 October 2017

Published online: 07 November 2017

\section{References}

1. Zaloshnja E, Miller T, Langlois JA, Selassie AW. Prevalence of long-term disability from traumatic brain injury in the civilian population of the United States, 2005. J Head Trauma Rehabil. 2008;23:394-400.

2. Shao J, Zhu H, Yao H, Stallones L, Yeates K, Wheeler K, et al. Characteristic and trends of pediatric traumatic brain injuries treated at a large pediatric medical centre in China, 2002-2011. PLoS One. 2012:7:e51634. https://doi. org/10.1371/journal.pone.0051634.

3. Da Dalt L, Marchi AG, Laudizi $L$, et al. Predictors of intracranial injuries in children after blunt head trauma. Eur J Pediatr. 2006;165:142-8.

4. Faul $M, X u L$, Wald MM, Coronado VG. Traumatic brain injury in the United States: emergency department visits, hospitalizations and deaths 2002-2006. Atlanta (GA): Centers for Disease Control and Prevention, National Center for Injury Prevention and Control; 2010.

5. Alyafei KA, Toaimah F, El Menyar A, Al Thani H, Youssef B, Mollazehi M, Consunji R. Analysis of pediatric trauma data from a hospital based trauma registry in Qatar. Int J Crit IIIn Inj Sci. 2015;5:21-6.

6. Cassidy LD, Potoka DA, Adelson PD, et al. Development of a novel method to predict disability after head trauma in children. J Pediatr Surg. 2003;38:482-5.

7. Rivara FP, Koepsell TD, Wang J, et al. Incidence of disability among children 12 months after traumatic brain injury. Am J Public Health. 2012;102(11):2074-9.

8. deGuise E, LeBlanc J, Feyz M, Meyer K, Duplantie J, Thomas H, Abouassaly M, Champoux MC, Couturier C, Lin H, et al. Long-term outcome after severe traumatic brain injury: the McGill interdisciplinary prospective study. J Head Trauma Rehabil. 2008:23:294-303.

9. Keenan HT, Bratton SL. Epidemiology and outcomes of pediatric traumatic brain injury. Dev Neurosci. 2006;28:256-63.

10. Ministry of Development Planning and Statistics, Population Topics, Retrieved Oct 292017 from http://www.mdps.gov.qa.

11. Hefny AF, Grivna M, Abbas AK, Branicki FJ, Abu-Zidan FM. Pediatric trauma research in the Gulf Cooperation Council countries. Asian J Surg. 2012;35:74-80.

12. Alhabdan S, Zamakhshary M, AlNaimi M, et al. Epidemiology of traumatic head injury in children and adolescents in a major trauma center in Saudi Arabia: implications for injury prevention. Ann Saudi Med. 2013;33:52-6.

13. El-Matbouly M, El-Menyar A, Al-Thani H, Tuma M, El-Hennawy H, Abdulrahman H, Parchani A, Peralta R, Asim M, El-Faramawy A, Zarour A, Latifi R. Traumatic brain injury in qatar: age matters- insights from a 4-year observational study. Sci World J. 2013:22:354920

14. El-Menyar A, Consunji R, Asim M, Abdelrahman H, Zarour A, Parchani A, Peralra R, Al-Thani H. Underutilization of occupant restraint systems in motor vehicle injury crashes: a quantitative analysis from Qatar. Traffic Inj Prev. 2015:17(3):284-91. https://doi.org/10.1080/15389588.2015.1069820.

15. Grivna, M., Barss, P, El-Sadig, M. Epidemiology and prevention of child injuries in the United Arab Emirates: a report for Safe Kids Worldwide, 2008. University Faculty of Medicine \& Health Sciences and Roadway Transportation \& Traffic Safety Research Center, Al Ain, UAE; 2008.

16. Raman, S.R., Landry, M.D., Ottensmeyer, C.A., Jacob, S., Hamdan, E., \& Bouhaimed, $M$. (in press). Keeping our children safe in motor vehicles: knowledge, attitudes and practice among parents in Kuwait regarding child car safety. Int I Inj Control Saf Promot doi:https://doi.org/10.1080/17457300.2012.745578.

17. Malik S; Saad R; Peralta R; Allen K; Hyder A; Al Thani H; Consunji R. Roadside observational surveys of restraint use by young children in Qatar: initial results and recommendations, Journal of Local and Global Health Science 2015:40 https://doi.org/10.5339/jlghs.2015.itma.40 17

18. Parchani A, El-Menyar A, Al-Thani $\mathrm{H}$, Tuma M, Zarour A, Abdulrahman $\mathrm{H}$, et al. Recreational-related head injuries in Qatar. Brain Inj. 2013;27:1450-3.

19. Grivna M, Eid HO, Abu-Zidan FM. Pediatric and youth traffic-collision injuries in Al Ain, United Arab Emirates: a prospective study. PLoS One. 2013;8(7): e68636. https://doi.org/10.1371/journal.pone.0068636

20. Assiry K, Abdulmutali H, Alqahtani A, Alyahya A, Elawad M. Traumatic head injuries in children: experience from Asir, KSA. Online J Med Med Sci Res. 2014:3(5):44-47. 20.

21. Consunji RJ, Peralta RR, Al-Thani H, Latifi R. The implications of the relative risk for road mortality on road safety programmes in Qatar. Inj Prev. 2015; 21(e1):e105-8. https://doi.org/10.1136/ injuryprev-2013-040939. 
22. Dewan MC, Mummareddy N, Wellons JC 3rd, Bonfield CM. Epidemiology of Global Pediatric Traumatic Brain Injury: Qualitative Review. World Neurosurg. 2016;91:497-509.e1.

23. Iranmanesh F. Outcome of head trauma in children. Indian J Pediatr. 2009; 76:929-31.

24. Fakharian E, Mohammadzadeh M, Behdad S, Babamohammadi A, Mirzadeh AS, Mohammadzadeh J. A seven-year study on head injuries in infants, Iran-the changing pattern. Chin J Traumatol. 2014;17(3):153-6.

25. Lotfi Sadigh S, Gholipour C, Vahdati SS, Ghafouri RR, Haghighi AG. Clinical predictors of abnormal computed tomography scan in minor head trauma in children under 2 years old. Anal Res Clin Med. 2015;3:57-63.

26. Alharthy N, Al Queflie S, Alyousef K, Yunus F. Clinical manifestations that predict abnormal brain computed tomography $(\mathrm{CT})$ in children with minor head injury. J Emerg Trauma Shock. 2015;8:88-93.

27. Yagmur F, Celik S, Yener Z, Koral F, Yaman T, Sezer Y, et al. Head traumarelated deaths among preschool children in Istanbul, Turkey. Am J Forensic Med Pathol. 2016;37:35-9.

28. Klimo P Jr, Ragel BT, Jones GM, McCafferty R. Severe pediatric head injury during the Iraq and Afghanistan conflicts. Neurosurgery. 2015;77:1-7. discussion: 7

29. Gofin R, Avitzour M. Outcome of head and other injuries among Israeli children: physical limitations and stress symptoms. Isr Med Assoc J. 2007;9:531-6.

Submit your next manuscript to BioMed Central and we will help you at every step:

- We accept pre-submission inquiries

- Our selector tool helps you to find the most relevant journal

- We provide round the clock customer support

- Convenient online submission

- Thorough peer review

- Inclusion in PubMed and all major indexing services

- Maximum visibility for your research

Submit your manuscript at www.biomedcentral.com/submit
Biomed Central 